\title{
Application Specific Microstructure Development in Microalloyed Bainitic Hot Strip
}

\author{
MENZEL Max ${ }^{1, a}$, HÖHNE Anastasia ${ }^{2, b}$, GEVELMANN Gerhard ${ }^{2, c}$, \\ TOMITZ Andreas $^{2, \mathrm{~d}}$, PRAHL Ulrich ${ }^{3, \mathrm{e}}$ and BLECK Wolfgang ${ }^{1, \mathrm{f}^{*}}$
}

${ }^{1}$ Institut für Eisenhüttenkunde, RWTH Aachen, Intzestraße 1, 52072 Aachen, Germany

${ }^{2}$ Thyssenkrupp Hohenlimburg GmbH, Oeger Str. 120, 58119 Hagen, Germany

${ }^{3}$ Institut für Metallumformung, TU Freiberg, Bernhard-von-Cotta-Str. 4, 09599 Freiberg, Germany

aMax.Menzel@iehk.rwth-aachen.de, bAnastasia.Hoehne@thyssenkrupp.com, 'Gerhard.Gevelmann@thyssenkrupp.com, ${ }^{\mathrm{d} A n d r e a s . T o m i t z @ t h y s s e n k r u p p . c o m, ~}$ eUlrich.Prahl@imf.tu-freiberg.de, 'Bleck@iehk.rwth-aachen.de

Keywords: Bainite, hot rolling, modelling, rate model, nucleation model

\begin{abstract}
During the hot rolling of bainitic steels, time and temperature must be controlled within narrow limits to avoid undesirable ferritic or martensitic phase fractions. In order to design a reliable process window for the production of bainitic steels, the effects of the different process parameters on the phase transformation and the final properties of a microalloyed and a non-microalloyed steel were investigated. Thermomechanical tests with the possibility of producing secondary samples were conducted to analyze the influence on the mechanical properties strength and toughness. Transmission electron microscopy (TEM) and electron probe micro analysis (EPMA) were used to investigate the origin of the differing properties. In particular, it has been found that thermomechanical rolling of the microalloyed steel leads to an improvement in strength. This is partly due to the transformation kinetics and partly to strain-induced precipitations. Further, the hardening behavior is affected by the secondary phase within the bainitic matrix configured through the cooling strategy. Coarse Martensite/Austenite (MA) structures reduce toughness, whereas finely dispersed MA islands increase the hardening potential. Furthermore, the results from the material experiments were used to develop a rate model in combination with a nucleation model to predict the kinetics of the phase transformation and the shape of the bainitic microstructure.
\end{abstract}

\section{Introduction}

Bainitic steels serve the applications where high strength is needed and increasingly substitute microalloyed steels [1]. The bainite transformation is rather complicated as it is partially diffusion controlled and the transformation mechanism and kinetics change with temperature $[2,3]$. Thus, the time-temperature profile in the strip on the run out table of a hot rolling mill must be controlled to lie in the most prompt bainite transformation temperature region so that the bainite transformation is the most feasible and unwanted phase transformation such as martensite or pearlite can be avoided. To ensure that the bainite transformation is promoted in the industrial process of hot rolling, the influence of the process parameters have to be known. Especially, in what kind they influence the transformation kinetics and the final microstructure. It is reported that with a higher degree of deformation the displacive transformation mechanism will end up more incomplete due to a higher dislocation density. The friction stress between the growing bainitic ferrite and the austenite is enlarged and hinders the further growth [4]. In addition, more nucleation site are available due to a smaller austenite grain and the increased number of dislocations. This shifts the start of the transformation to higher temperatures $[5,6]$. Further, the shape of the bainitic structure does influence the mechanical properties of the final product [7]. This is related to the structure of the bainitic ferrite and the different shapes the secondary phase can develop [8]. The purpose of this work is to investigate, to what extend the deformation of the austenite can influence the mechanical properties of bainitic steels. And further, to develop a model based on the approach by Leblond and Devaux [9] in combination with the microstructural modelling by Azuma [10] that can predict the bainitic phase transformation during the cooling line in the hot rolling process. 


\section{Experimental Procedure}

Materials. Two steel concepts for the production of hot rolled bainitic steels were investigated. The chemical compositions are shown in Table 1. The materials were produced in a vacuum furnace and pre-rolled to a thickness of $55 \mathrm{~mm}$. Further, samples of a size $65 \times 16 \times 16 \mathrm{~mm}$ have been machined for the investigation in the Thermomechanical Treatment Simulator.

Table 1. Chemical compositions of investigated steel grades (mass\%)

\begin{tabular}{ccccccc}
\hline & C & Si & Mn & Cr & Mo + Ti + B & Nb + V \\
\hline Steel A & 0.06 & 0.20 & 0.7 & 0.4 & $<0.05$ & - \\
\hline Steel B & 0.1 & 0.45 & 1.7 & 0.3 & $<0.4$ & $<0.1$ \\
\hline
\end{tabular}

Experiments. The samples have been processed in a Thermomechanical Treatment Simulator, shown in Fig. 1a. The applied thermomechanical cycle is illustrated in Fig. 1b. The materials have been annealed for 25 minutes at $1250{ }^{\circ} \mathrm{C}$ followed by two deformation steps at $1150{ }^{\circ} \mathrm{C}$ and $950{ }^{\circ} \mathrm{C}$. The cooling rate between the deformation steps has been $15 \mathrm{~K} / \mathrm{s}$. In the second deformation step, the degree of deformation has been varied. Afterwards, B $3 \times 15$ tensile samples and smallest charpy samples $(4 \times 3 \times 27 \mathrm{~mm}$ ) have been machined out of the deformed region to analyze the mechanical properties.
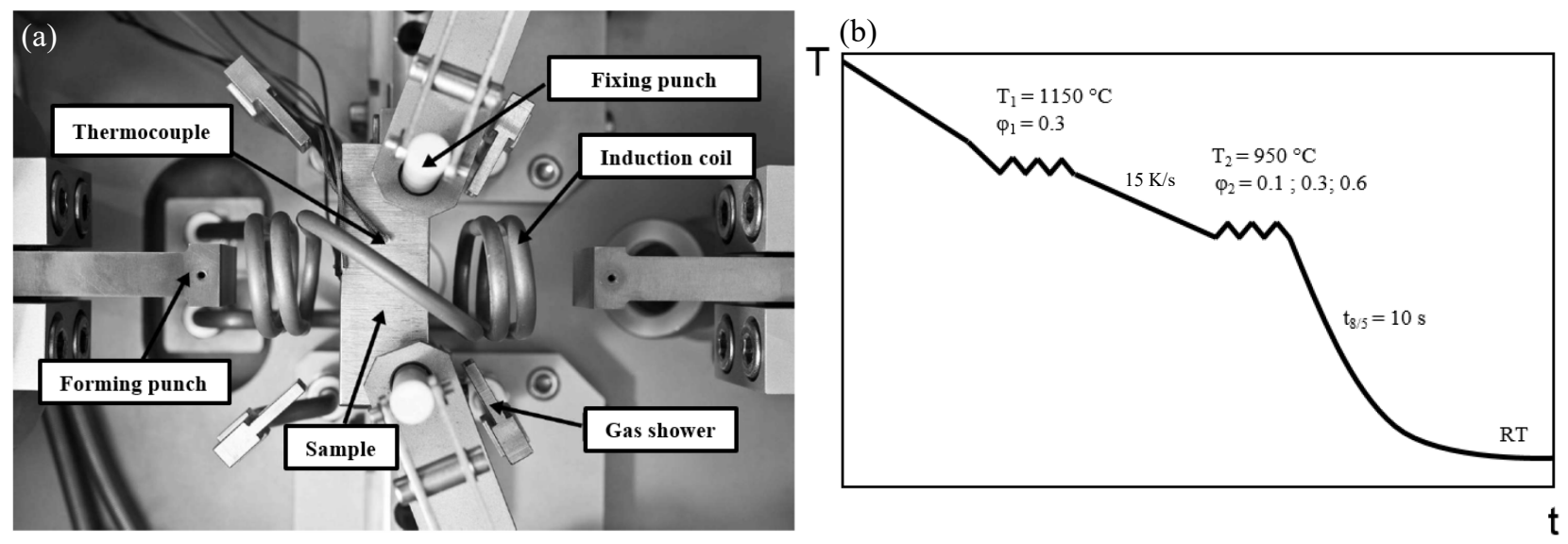

Figure 1. (a) Thermomechanical Treatment Simulator. (b) The applied thermomechanical cycle

Microstructure Investigations. SEM pictures have been taken to analyze the achieved microstructure. The phase fractions have been evaluated with an image analysis based on the approach by Lehto [14]. Since a microalloyed steel has been investigated, carbon replicas have been examined in a transmission electron microscope to identify different kinds of precipitates. Furthermore, EPMA was used to identify the influence of the austenite conditioning on the carbon partitioning. Especially, the carbon content of the MA islands was of interest.

Pilot Rolling. In addition to the laboratory tests, pilot rolling was carried out on the pilot production of thyssenkrupp Steel Europe AG in Dortmund. The rolling parameters were selected on the basis of the process parameters previously determined in the laboratory tests and through the application of the developed model. Pre-rolled material in the form of small slabs (180 $\mathrm{mm} \times 120 \mathrm{~mm} \times 55 \mathrm{~mm})$ was used. The material was first heated to $1250{ }^{\circ} \mathrm{C}$, then descaled and reversibly rolled in five rolling passes to a final thickness of $3 \mathrm{~mm}$. The first four rolling passes were applied at $1100-1000{ }^{\circ} \mathrm{C}$. The final rolling pass was applied at $960{ }^{\circ} \mathrm{C}$ to reach the final rolling temperature (FRT) with a previously defined degree of deformation ( $\left.\varphi_{\text {finish }}\right)$. The detailed process parameters can be found in Table $2 . T_{\mathrm{EC}}$ represents the temperature at the end of the cooling line. After passing the cooling line, the materials were put into a furnace with temperature CT to simulate the coiling process. 
Table 2. Process parameters during pilot rolling

\begin{tabular}{cccccc}
\hline Material & $\boldsymbol{\varphi}_{\text {finish }}$ & FRT $\left[{ }^{\circ} \mathbf{C}\right]$ & $\begin{array}{c}\text { Cooling Rate } \\
{[\mathbf{K} / \mathbf{s}]}\end{array}$ & $\mathbf{T}_{\mathrm{EC}}\left[{ }^{\circ} \mathbf{C}\right]$ & $\mathbf{C T}\left[{ }^{\circ} \mathbf{C}\right]$ \\
\hline Steel A_TR1 & 0.5 & 905 & 50 & 510 & 450 \\
\hline Steel A_TR2 & 0.2 & 900 & 120 & 435 & 450 \\
\hline Steel B_TR1 & 0.6 & 910 & 50 & 500 & 490 \\
\hline Steel B_TR2 & 0.2 & 910 & 30 & 515 & 490 \\
\hline
\end{tabular}

\section{Results}

The mechanical properties of Steel A were nearly unaffected by the different deformation states, Table 3. The diverse deformed samples of Steel B showed different strength and elongation values. The yield strength has been increased by $33 \mathrm{MPa}$. Further, the tensile strength is increased by $92 \mathrm{MPa}$ from $818 \mathrm{MPa}$ to $910 \mathrm{MPa}$ due to a change in the degree of deformation from $\varphi=0.1$ to $\varphi=0.4$. In addition, the elongation is increased by $5 \%$. The yield ratio decreases with increasing degree of deformation. The influence of the degree of deformation on the fracture behavior of Steel B is also remarkable. The absorbed energy increased with higher degree of deformation. The fracture behavior became ductile. The experimental results are shown in Table 1. For each condition, two samples have been tested. Exemplary images of the microstructural investigation of both steels are shown in Fig. 2 .

Table 3. Mechanical Properties of the investigated steel under different degrees of deformation

\begin{tabular}{cccccccc}
\hline Steel & $\boldsymbol{\varphi}_{\mathbf{2}}$ & $\begin{array}{c}\mathbf{R}_{\mathbf{p 0 , 2}} \\
{[\mathbf{M P a}]}\end{array}$ & $\begin{array}{c}\mathbf{R}_{\mathbf{m}} \\
{[\mathbf{M P a}]}\end{array}$ & $\begin{array}{c}\mathbf{R}_{\mathbf{p 0 , 2}} / \mathbf{R}_{\mathbf{m}} \\
{[\mathbf{M P a}]}\end{array}$ & $\begin{array}{c}\mathbf{A}_{\mathbf{g}} \\
{[\mathbf{\%}]}\end{array}$ & $\begin{array}{c}\mathbf{A}_{\mathbf{5}} \\
{[\mathbf{\%}]}\end{array}$ & $\begin{array}{c}\mathbf{A v} \\
{[\mathbf{J}]}\end{array}$ \\
\hline $\mathbf{A}$ & 0.1 & 483 & 599 & 0.81 & 6.3 & 17.9 & 10.5 \\
\hline $\mathbf{A}$ & 0.3 & 488 & 603 & 0.81 & 6.6 & 18.4 & 10.5 \\
\hline $\mathbf{A}$ & 0.6 & 484 & 598 & 0.81 & 7.2 & 18.6 & 10.7 \\
\hline B & 0.1 & 562 & 818 & 0.70 & 5.5 & 10.4 & 2.5 \\
\hline B & 0.3 & 571 & 843 & 0.68 & 5.8 & 14.5 & 9.9 \\
\hline B & 0.4 & 595 & 910 & 0.65 & 6.9 & 15.3 & 9.7 \\
\hline
\end{tabular}

The microstructure of Steel A consists of bainitic ferrite with carbide precipitations. Since the mechanical properties and the microstructure are unaffected due to different deformation parameters, only Steel B will be further investigated. For every condition of Steel B the microstructure mainly consists of granular bainitic ferrite with MA constituents and occasional carbides. The measured microstructural characteristics of the three conditions are summarized in Table. 4. The size of the primary phase, the bainitic ferrite, is decreased with increasing degree of deformation. Further, the size of the secondary phase particles is nearly unaffected and is only increased slightly. In contrast, the fraction of the secondary phase does increase from 0.14 to 0.24 .

The TEM investigations of the carbon replicas indicate that the austenite deformation does influence the precipitation kinetics. It turns out that with a higher degree of deformation, an increased number of fine precipitates occurs in the microstructure, as shown in Fig. 3. Further EDX investigations identified the particles as TiMoNb precipitates with a size of $3-10 \mathrm{~nm}$.

In addition, the influence of the austenite deformation on the carbon content of the MA islands was investigated by electron beam microanalysis. Fig. 4 shows the results of a representative line scan for every state. As the degree of deformation increases, so does the carbon content in the MA constituents. For $\varphi=0.1$, the carbon content of the measured MA structures is $0.3-0.4$ wt. \%. For the sample with $\varphi=0.3$, the $\mathrm{C}$ content could be measured at $0.4-0.5$ wt. $\%$. For the state with the highest degree of deformation with $\varphi=0.4$, the $\mathrm{C}$ content of the MA structures is on average $0.5-0.6$ wt. $\%$. 

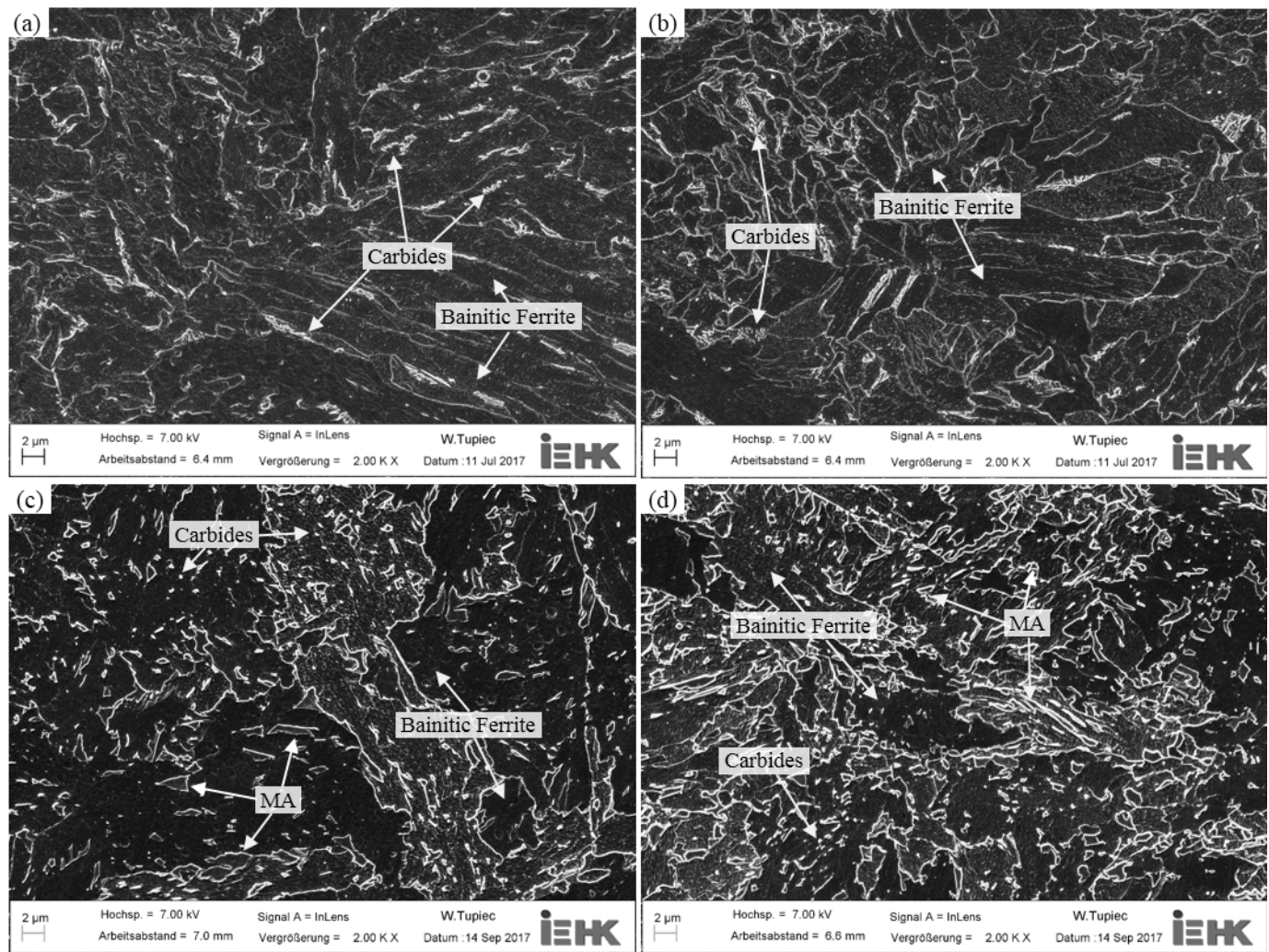

Figure 2. SEM pictures of (a) Steel A processed with $\varphi=0.1$ (b) Steel A, $\varphi=0.6$ (c) Steel B, $\varphi=0.1(\mathrm{~b})$ Steel B, $\varphi=0.4$

Table 4. Microstructural characteristics of the different processed conditions of Steel B

\begin{tabular}{ccccc}
\hline Steel & $\boldsymbol{\varphi}_{2}$ & $\begin{array}{c}\text { Primary Phase } \\
{[\boldsymbol{\mu m}]}\end{array}$ & $\begin{array}{c}\text { Secondary } \\
\text { Phase }[\boldsymbol{\mu \mathrm { m }}]\end{array}$ & $\begin{array}{c}\text { Volume Fraction } \\
\text { Secondary Phase }\end{array}$ \\
\hline B & 0.1 & 4.1 & 0.66 & 0.14 \\
\hline B & 0.3 & 2.8 & 0.68 & 0.20 \\
\hline B & 0.4 & 2.2 & 0.74 & 0.24
\end{tabular}
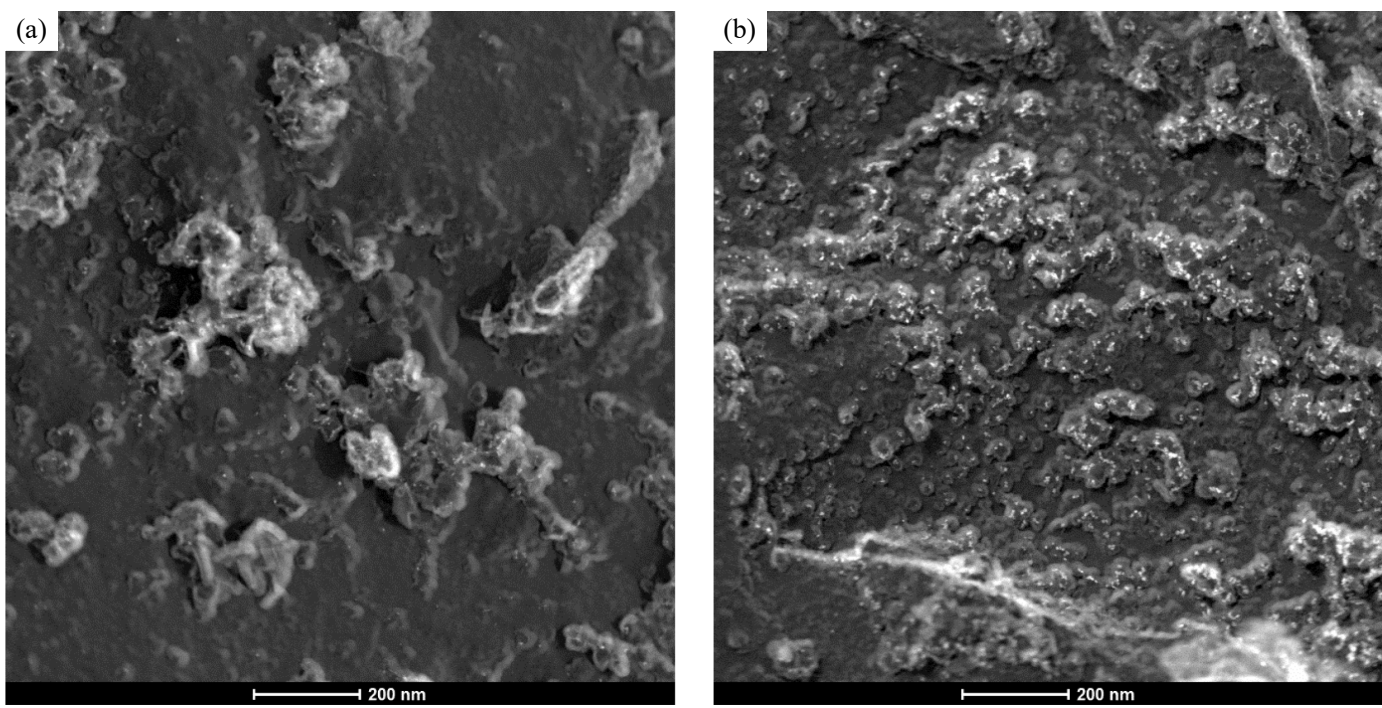

Figure 3. TEM images with 40,000 magnitude of the carbon replica of the processed samples with (a) $\varphi=0.1$ (b) $\varphi=0.4$ 

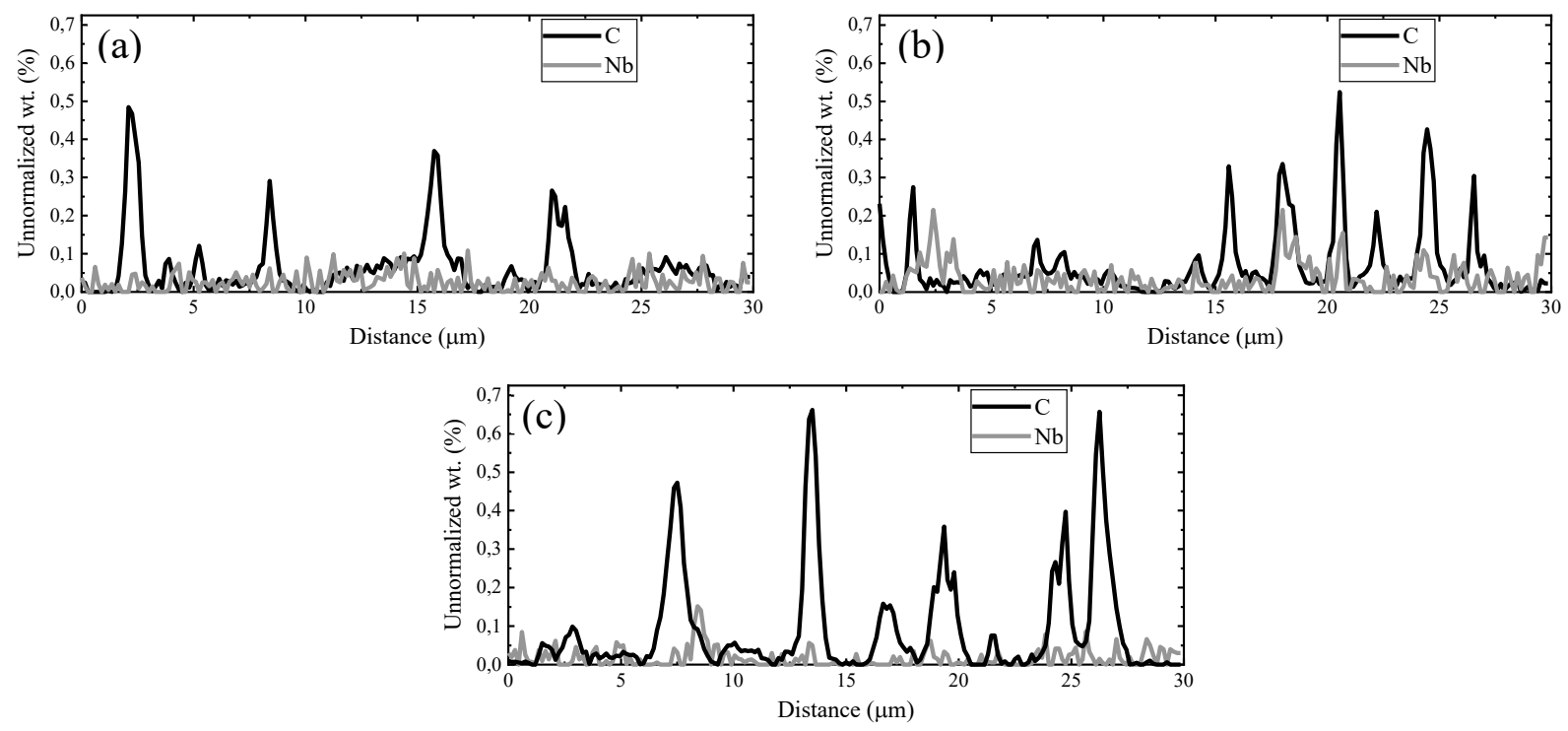

Figure 4. Results of the EPMA investigation illustrating the carbon content in the MA structures of Steel B (a) $\varphi=0.1$ (b) $\varphi=0.3$ (c) $\varphi=0.4$

\section{Modelling Work}

The basic approach of the model is based on Leblond and Devaux [9] and was further established by Hömberg and Weiss [11]. It was also used to describe the phase transformation in DP and TRIP steels during an isothermal transformation [12]. In this work, a new approach with the aim to describe the bainitic phase transformation during a continuous cooling profile has been developed. In Eq. 1, the term for the bainitic transformation rate is given [13].

$$
\dot{\mathrm{b}}=\left[\mathrm{b}_{\max }\left(\mathrm{C}_{\gamma}, \mathrm{T}\right)-\mathrm{b}\right] \mathrm{g}_{\text {biso }}(\mathrm{T}) \mathrm{g}_{\mathrm{bcon}}(\dot{\mathrm{T}}) \mathrm{g}_{\mathrm{bc}}\left(\mathrm{C}_{\gamma}\right) \mathrm{g}_{\mathrm{bdef}}\left(\mathrm{D}_{\gamma}, \varepsilon\right)
$$

The maximum achievable bainite fraction $\mathrm{B}_{\max }$ is to be identified from CALPHAD method and is a function of carbon and temperature as proposed by Takahashi [14]. The term $\mathrm{g}_{\mathrm{bcon}}$ reflects the influence of the cooling strategy and has to be identified from dilatometer experiments. $g_{b c}$ means the function of carbon content in the austenite. The last term $\mathrm{g}_{\mathrm{bdef}}$ contributes to the austenite conditioning, in terms of austenite grain size and retained strain before the transformation. The model code was executed with MATLAB R2017a. A detailed description of the estimation of the different terms can be found elsewhere [15]. Further, the nucleation model by Azuma [10] was utilized to model the shape of the bainitic ferrite and the secondary phase. The phase fraction of bainite was still calculated via the rate model.

\section{Model Application}

The model was first used in a trial rolling. Fig. 4a shows the modelled phase fraction of Steel A influenced by the different process parameters. During the trial rolling 2 (TR2) the material was less strong deformed but cooled much faster. This results in an accelerated transformation kinetic. Further, representative stress-strain curves of both materials are shown. For Steel A the yield strength is increased, but the elongation significantly lowered due to the rapid cooling. Due to faster cooling and a lower deformation, the yield strength and tensile strength of Steel B are influenced. Table 5Table illustrates the microstructural characteristics measured from the rolled sheets and the modelling results. 

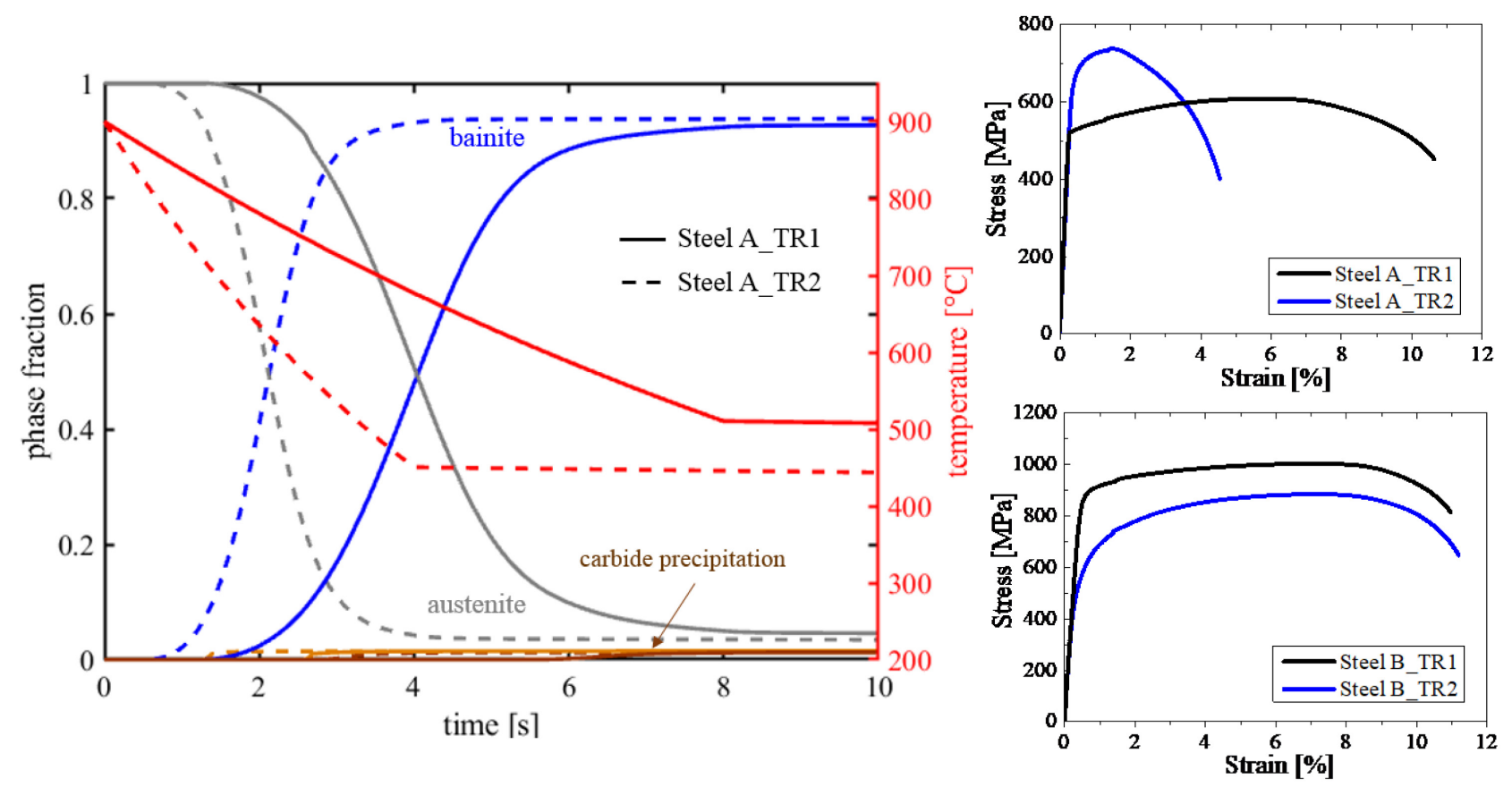

Figure 5. (a) Modelled phase fractions from the trial rolling (b) Stress-Strain-Curves from trial rolling of Steel A (b) Stress-Strain Curves from trial rolling of Steel B

Table 5. Comparison of experimentally determined microstructure characteristics with the modelled results

\begin{tabular}{ccccc}
\hline \multirow{2}{*}{ Material } & \multicolumn{2}{c}{ Experimental Results } & \multicolumn{2}{c}{ Modelling Results } \\
\cline { 2 - 5 } & $\begin{array}{c}\text { Primary Phase } \\
{[\boldsymbol{\mu \mathrm { m } ]}}\end{array}$ & $\begin{array}{c}\text { Secondary Phase } \\
{[\boldsymbol{\mu \mathrm { m } ]}}\end{array}$ & $\begin{array}{c}\text { Primary Phase } \\
{[\boldsymbol{\mu \mathrm { m } ]}}\end{array}$ & $\begin{array}{c}\text { Secondary Phase } \\
{[\boldsymbol{\mu m}]}\end{array}$ \\
\hline Steel A_TR1 & 3,9 & 0,33 & 4,8 & 0,53 \\
\hline Steel A_TR2 & 1,8 & 0,34 & 1,6 & 0,27 \\
\hline Steel B_TR1 & 1,4 & 0,36 & 2,1 & 0,42 \\
\hline Steel B_TR2 & 3,7 & 0,54 & 3,1 & 0,53 \\
\hline
\end{tabular}

\section{Discussion}

Materials. Two different steel grades have been investigated and they especially differ regarding their microalloying content. Steel A has only alloyed a small amount of Ti. After Barbosa [16] the temperature of no recrystallization $\left(\mathrm{T}_{\mathrm{NR}}\right)$ can be estimated around $870^{\circ} \mathrm{C}$. For Steel B this temperature is near $1000^{\circ} \mathrm{C}$. Since the properties of Steel A were nearly unaffected in the laboratory experiments, it must be distinguished, whether the austenite does recrystallize before the transformation. Therefore, for the further discussion Steel B will be focused.

Microstructure. From a consideration of the microstructure and the separate analysis of the primary and secondary phase, it has been found that with increasing degree of deformation the size of the primary phase decreases and the volume fraction of the secondary phase does increase. It has already been showed that the bainite formation is shifted to higher temperatures due to the deformation of the austenite [15]. The size of the MA islands is not influenced on average. The higher levels of granular secondary phase can be correlated with the slower rate of transformation by a reduced austenite grain. Further it has been indicated, that the transformed fraction does decrease and a higher amount of MA constituent is observed $[7,16]$. The higher dislocation density in the austenite increases the friction stress between the growing bainitic ferrite and the strengthened austenite. This results in smaller bainite packages und a lower amount of transformed fraction [7]. 
Precipitations. In addition to the influence on the microstructural appearance, the influence of the deformation of the austenite on the precipitation characteristics was demonstrated by the examination of carbon replicas in the TEM. Due to an increased degree of deformation a significantly higher number of finely distributed precipitates are formed. These have a size of $3-10 \mathrm{~nm}$ and thus fall in the range for precipitation hardening. It already has been observed that $\mathrm{Ti}$ in combination with Mo results in a considerable strength-increasing effect. The addition of $0.2 \mathrm{Mo}$ and $0.09 \mathrm{Ti}$ increased the yield strength and tensile strength by more than $350 \mathrm{MPa}$ [17]. Further, is has been shown that the precipitation kinetics of $\mathrm{Ti}$ precipitates are favored, especially in the temperature range around $1000-900{ }^{\circ} \mathrm{C}$ [18]. This is precisely the temperature range at which the last deformation step in the process takes place, what further underlines the importance of controlling this process parameter.

Carbon Distribution. Increasing the degree of deformation increases the free energy of the austenite and creates new nucleation sites for the phase transformation. This inevitably results in a higher transformation temperature, which is beneficial for diffusion. Further, the decomposition of the austenite can begin before the transformation starts [19]. In the higher temperature region the diffusion is favored, which leads to an increased carbon content in the austenite. Carbide precipitation does not occur. The microstructure consists of partly granular bainitic ferrite and MA islands. At lower temperatures, the diffusivity of carbon is limited what promotes the formation of carbides and thus the lower bainite formation. A sufficient accumulation of carbon to stabilize the MA structures is prevented and carbides are precipitated in the bainitic ferrite. It already has been shown that with increasing cooling rate the carbon content in the MA constituents decreases [20], which supports this assumption. In addition, the state of the austenite shortly before the phase transformation starts does influence the decomposition. Higher deformation degrees reduce the austenite grain size what results in smaller bainitic packages. Further, due to the increased friction stress between the growing bainitic ferrite and the strengthend austenite the transformation stops mor incomplete. This results in higher proportions of MA [21]. On the one hand, the higher transformation temperature promotes diffusion, and on the other hand, the diffusion paths are shortened through the fined microstructure. Thus, a smaller austenite grain leads to an increased proportion of finely divided MA islands with increased carbon content. This could be shown by the EPMA investigations. The carbon content of the MA islands increases with increasing degree of deformation.

Model Evaluation. When applying the combined modelling approach, it was observed that the influences of the process parameters on the microstructure determined in the material tests can be considered and reproduced. This applies in particular to the influence of the cooling rate and the forming parameters on the size of the primary phase. This enables the prediction of the influence on the mechanical properties to a certain extent via the model application. The predictability of the secondary phase could only be evaluated to some extent in this work. The differentiation of the secondary phase with regard to the place of precipitation and also the size is not possible without some uncertainty on the basis of the experimental methods used. However, the size of the MA islands could be predicted by the model application in the correct magnitude. As shown, the manifestation of this phase has the most significant influence on the properties of the final product and can therefore be called a target in further model development. One of the major challenges in future model application in the industrial environment are the significantly changed process conditions compared to the laboratory scale. These have to be depicted realistically, since a model application would otherwise only have a very low significance.

\section{Conclusions}

The properties of the non microalloyed bainitic steel are insensitive to the process parameters due to the transformation of recrystallized austenite. However, it has been shown that the deformation of austenite does influence the final properties of a microalloyed bainitic steel. Especially, the shape of the secondary phase does influence the mechanical properties. Finer MA islands, related to the smaller austenite grain and the higher dislocation density, improve the hardenability of these 
materials. Further, the strain induced TiMoNb precipitates increase the strength and the MA constituents are enriched with carbon. The rate model, further developed by process variables and thermodynamic parameters, enables a process design so that the transformation takes place selectively in the cooling line (anisothermal) or in the coil (isothermal). The modeling of the microstructural characteristics allows conclusions about the influence of the process parameters on the final properties.

\section{Acknowledgments}

The work has been done in the framework of the knowledge transfer project "Application of a Fast Phase Transformation Model on the Run Out Table of a Narrow Strip Hot Rolling Mill" in cooperation with thyssenkrupp Hohenlimburg $\mathrm{GmbH}$ funded by the Deutsche Forschungsgemeinschaft (DFG).

\section{References}

[1] V. C. Igwemezie, P. C. Agu, Development of Bainitic Steels for Engineering Applications, Int. J. Eng. Res. Tech. 2 (2014) 2698-2711

[2] H. K. D. H. Bhadeshia, The bainite transformation: unresolved issues, Mat. Sci. Eng. A (1999) 58-66

[3] R. F. Hehemann, The bainite reaction, Am. Soc. Met. (1970) 397-432

[4] A. Matsuzaki, H. K. D. H. Bhadeshia, Effect of austenite grain size and bainite morphology on overall kinetics of bainite transformation in steels, Mat. Sci. Tech. 5 (2013) 518-522

[5] P. Shipway, H. K. D. H. Bhadeshia, Mechanical stabilisation of bainite, Mat. Sci. Tech. 11 (1995) 1116-1128

[6] S. J. Lee, J. S. Park, Y. K. Lee, Effect of austenite grain size on the transformation kinetics of upper and lower bainite in a low-alloy steel, Scr. Mat. 1 (2008) 87-90

[7] C. Y. Huang, J. R. Yang, S. C. Wang, Effect of Compressive Deformation on the Transformation Behavior of an Ultra-Low-Carbon Bainitic Steel, Mat. Trans. 8 (1993) 658-668

[8] F. G. Caballero, C. Capdevila, J. Chao, J. Cornide, C. Garcia-Mateo, H. Roelofs, S. Hasler, G. Mastrogiacomo, The microstructure of continuously cooled tough bainitic steel. International Conference Super-High Strength Steels. Milano (2010)

[9] J. B. Leblond, J. Devaux, A new kinetic model for anisothermal metallurgical transformations in steels including effect of austenite tgrain size, Acta metall. mater. 1 (1984) 137-146

[10] M. Azuma, M. Fujita, M. Takahashi, T. Senuma, D. Quidort, T. Lung, Modelling Upper and Lower Bainite Transformation in Steels, ISIJ International. 2 (2005) 221-228

[11] D. Hömberg, A numerical simulataion of the jominy end-quench test, Acta Mat. 11 (1996) 43754385

[12] P. Suwanpinij, N. Togobytska, U. Prahl, W. Weiss, D. Hömberg, W. Bleck, Numerical Cooling Strategy Design for Hot Rolled Dual Phase Steel, Ste. Res. Int. 11 (2010) 1001-1009

[13] P. Suwanpinij, X. Li, U. Prahl, W. Bleck, Modeling Bainite Transformation and Retained Austenite in Hot Rolled TRIP Steel by Instantaneous Carbon Enrichment, steel research int. 12 (2017) 1700122

[14] M. Takahashi, H. K. D. H. Bhadeshia, A Model for the Microstructure of Some Advanced Bainitic Steels, Mat. Trans. 8 (1991) 689-696

[15] M. Menzel, Anwendungsspezifische Gefügeentwicklung in mikrolegiertem bainitischem Warmband. RWTH Aachen. Aachen (not published yet) 
[16] R. Barbosa, F. Boratto, S. Yue, J. J. Jonas, The influence of chemical composition on the recrystallisation behaviour of microalloyed steels, International symposium on processing, microstructure and properties of HSLA steel (1988) 51-61

[17] M. P. Phaniraj, Y.-M. Shin, W.-S. Jung, M.-H. Kim, I.-S. Choi, Understanding dual precipitation strengthening in ultra-high strength low carbon steel containing nano-sized copper precipitates and carbides, Nano convergence. 1 (2017) 16

[18] Z. Wang, X. Mao, Z. Yang, X. Sun, Q. Yong, Z. Li, Y. Weng, Strain-induced precipitation in a Ti micro-alloyed HSLA steel, Materials Science and Engineering: A (2011) 459-467

[19] H. K. D. H. Bhadeshia, Atomic Mechanism of the Bainite Transformation, HTM. 6 (2017) 340345

[20] H. F. Lan, L. X. Du, X. H. Liu, Microstructure and Mechanical Properties of a Low Carbon Bainitic Steel, steel research int. 4 (2013) 352-361

[21] S. Chatterjee, H.-S. Wang, J. R. Yang, H. K. D. H. Bhadeshia, Mechanical stabilisation of austenite, Mat. Sci. Tech. 6 (2013) 641-644 